\title{
Mitsuokella Jalaludinii Supplementation Improved Nutrient Utilization of Broilers Fed Low-Available Phosphorus Diet
}

\section{-Author(s)}

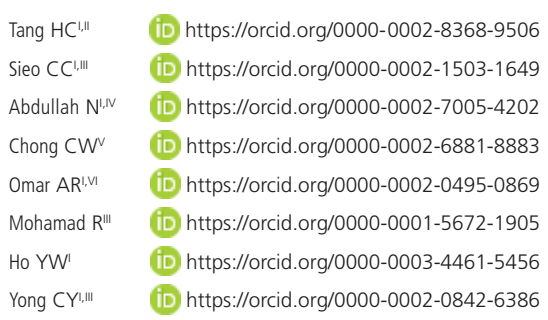

Institute of Bioscience, Universiti Putra Malaysia, Serdang, Selangor, Malaysia.

International Medical School, Management and Science University, Seksyen 13, 40100 Shah Alam, Selangor, Malaysia

II Department of Microbiology, Faculty of Biotechnology and Biomolecular Sciences, Universiti Putra Malaysia, Serdang, Selangor, Malaysia.

Institute of Tropical Agriculture and Food Security, Universiti Putra Malaysia, Serdang, Selangor, Malaysia.

School of Pharmacy, Monash University - Malaysia Campus, Bandar Sunway, Selangor, Malaysia.

Department of Veterinary Pathology \& Microbiology, Faculty of Veterinary Medicine, Universiti Putra Malaysia, Serdang, Selangor, Malaysia.

\section{Mail Address}

Corresponding author e-mail address Abdul Rahman Omar

Department of Veterinary Pathology \& Microbiology Faculty of Veterinary Medicine - Universiti Putra Malaysia 43400 Serdang, Selangor, Malaysia.

Phone: +03-89468268

Email: aro@upm.edu.my

\section{- Keywords}

Broiler, mineral retention, Mitsuokella jalaludinii, nutrient utilization, phytase.

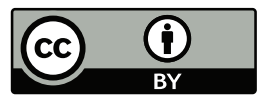

Submitted: 04/June/2020

Approved: 15/October/2020

\section{ABSTRACT}

Phytase enzyme is supplemented to poultry feed to improve phosphorus (P) availability. Mitsuokella jalaludinii, bacteria isolated from the rumen of cattle, has been reported as a cheaper alternative source of phytase. As much nutrients are trapped within the phytate complex, we hypothesized that the supplementation of $M$. jalaludinii phytase to poultry feed would enhance nutrient utilization by poultry. In the current study, the efficacy of freeze-dried M. jalaludinii cells (Mj) as feed supplement for broilers fed low-available phosphorus (low-aP) diet was evaluated. Day-old male Cobb raised in battery cages were assigned to three treatment groups [normal-available phosphorus diet with heat-deactivated $\mathrm{Mj}$ (DMj); low-aP diet with $\mathrm{DMj}$; and low-aP diet with Mi], each consisting of four replicates (10 birds per replicate) for a 3 -weeks feeding period. Feed intake was recorded daily from day 1-21, whereas broilers were weighted at day $1,7,14$, and 21 . Total excreta were collected at day 11-13 and 18-20. At day 21, twelve broilers from each treatment group were slaughtered to collect plasma and tibia. The results showed that Mj significantly enhanced broilers' live weight and feed conversion ratio compared to the control groups $(p<0.05)$. Supplementation with $\mathrm{Mj}$ have also enhanced the level of $\mathrm{P}, \mathrm{Ca}, \mathrm{Mn}, \mathrm{Cu}$, and $\mathrm{Zn}$ in the sera; and $\mathrm{Ca}$ and $\mathrm{Mn}$ in the tibia at day $18-20$ sampling period $(p<0.05)$. As Mj supplementation can enhance nutrient utilization particularly in broilers fed with low-aP diet, it could provide the market with another option in improving broilers' growth rate at a lower cost.

\section{INTRODUCTION}

Phosphorus $(\mathrm{P})$ is one of the most important macro-minerals required by poultry as it is essential for the development and maintenance of the skeletal system as well as in numerous biochemical reactions in the body and being a part of many important metabolites involved in metabolic processes, such as phosphates used for energy, and the synthesis of DNA and RNA (Haque \& Hossain 2012).

The main ingredients in poultry feed such as cereal grains and plant protein sources have high phosphorus content presence mainly in the form of phytate (up to $80 \%$ of total P), which is poorly utilized in monogastric animals including poultry. Phytate (the salt form of phytic acid, inositol-6-phosphate) can bind proteins and minerals as well as interact with endogenous enzymes, thus reducing nutrient utilization (Selle et al. 2012). It exerts negative effect on protein digestion either through the direct binding of proteins to phytates, forming binary protein-phytate complexes or through the binding of proteins to the ions attached to phytates, forming ternary protein-phytate complexes. These phytate complexes can be found in plant feedstuffs naturally, and the majority of the complexes may form within the gastrointestinal 
tract of the animals due to the presence of many metal cations (Selle et al., 2000).

Phytases are enzymes that break down phytate by hydrolysing its phosphate groups and at the same time, releasing its chelated or bound nutrients such as minerals, proteins and starches (Qvirist et al., 2017). In order for monogastric animals to utilize the bound nutrients, degradation of phytate is necessary by exogenous phytase since monogastric animals do not have enough phytase enzymes in the intestinal tract. The supplementation of exogenous phytase enzyme has become a regular practice in monogastric animal nutrition to overcome the anti-nutritive effects of phytates. As phytase supplementation increases $P$ availability, it reduces the need for addition of inorganic $P$ into poultry feed, thus reduces $P$ pollution which causes eutrophication in land water bodies (Bhavsar \& Khire 2014).

A bacterial species, locally isolated from the rumen of cattle, known as Mitsuokella jalaludinii, was able to produce phytase with activity comparable to the commercial phytase enzyme Natuphos ${ }^{\circledR}$ (Lan et al., 2012). Not only does the enzyme have wider working $\mathrm{pH}$ range, it can also function in the presence of metal chelating agents. In addition, $M$. jalaludinii phytase is a cheaper alternative to conventional phytase, as it is produced through semi-solid state fermentation using agricultural by-products, where the phytase supplementation was added to the feed in form of freeze-dried bacteria (Tang et al., 2018; Tang et al., 2020; Tang et al., 2017). Previously, we have demonstrated that the $M$. jalaludinii phytase supplementation to low-available phosphorus (aP) diet was able to improve broilers' body weight gain and feed conversion ratio (FCR) independent to the caeca microflora (Tang et al., 2020). In the current research, we attempt to study the nutrient retention, particularly on phosphorus $(\mathrm{P})$, calcium (Ca), manganese $(\mathrm{Mn})$, copper $(\mathrm{Cu})$, and zinc $(\mathrm{Zn})$ in broilers fed with lowaP diet supplemented with freeze-dried $M$. jalaludinii cells containing functional phytase activity (Mj). Additionally, the nutrient concentration in the bone and blood of the broilers were also measured to study the effect of $M$. jalaludinii phytase supplementation towards prevention of nutrient leaching.

\section{MATERIALS AND METHODS}

\section{Ethics statement}

This study was carried out in accordance with the guidelines and approval by the Institutional Animal Care and Use Committee (IACUC) of Universiti Putra
Malaysia (UPM) with the reference number: UPM/ IACUC/AUP-R14/2015 with respect to animal welfare ethics and animal management.

\section{Phytase production}

Phytase from $M$. jalaludinii was produced under anaerobic condition by semi-solid state fermentation process at $39^{\circ} \mathrm{C}$ for $12 \mathrm{~h}$ using rice bran and fish meal as substrates, as described in Tang et al. (2018). The fermented substrate was filtered and the filtrate was centrifuged at $10,000 \times g$ for $20 \mathrm{~min}$. The pellets obtained were washed twice with normal saline $(0.85 \%$ $\mathrm{NaCl}$ ) to remove spent substrates. The pellets collected were either freeze-dried or oven dried at $65^{\circ} \mathrm{C}$ for 72 $\mathrm{h}$ for the preparation of active (Mj) and deactivated (DMj) M. jalaludinii phytase, respectively. The absence of phytase activity in DMj was confirmed as described by Yanke et al. (1998) and Heinonen \& Lahti (1981). The dried $M$. jalaludinii cells were ground through 1 $\mathrm{mm}$ sieve. The active Mj enzyme was added to the low-available P (low-aP) diet at the level of $500 \mathrm{U} / \mathrm{kg}$ feed. Same amount of DMj was added to the normalavailable P (normal-aP) and low-aP diet as controls.

\section{Diet preparation}

The ingredients and nutrient composition of the experimental diets are summarized in Table 1. The nutrient composition of both normal-aP and low-aP diets was the same, except the aP in low-aP diet was lower than in the normal diet. All diets were maintained iso-nitrogenous and iso-caloric by adding equal amount of freeze-dried and thermally inactivated oven-dried $M$. jalaludinii cells. The three experimental diets were low-aP+Mj, normal-aP+DMj, and low-aP+DMj. The Mj and DMj were mixed daily with the other ingredients manually before the morning feeding.

\section{Broilers management and experimental design}

A 3-weeks feeding experiment with completely randomized design was conducted. One hundred and twenty male Cobb (day-old), purchased from a local hatchery were assigned to three dietary treatments with four replicates (10 birds per replicate). The birds were reared in battery cages in a well-ventilated open house.

\section{Sample collection}

Daily feed intake was recorded for each replicate and live weight of broilers (1-day, 7-days, 14-days, and 21-days old) was determined weekly for the calculation of feed conversion ratio (FCR). At day 21, 
Table 1 - Ingredients and nutrient compositions of normalavailable $p$ and low-available $p$ diets.

\begin{tabular}{|c|c|c|}
\hline Ingredient $(\mathrm{g} / \mathrm{kg})$ & Normal-aP & Low-aP \\
\hline Corn & 542.63 & 551.02 \\
\hline Soybean meal & 366.92 & 366.92 \\
\hline Fish meal & 19.99 & 19.99 \\
\hline Palm oil & 39.88 & 36.98 \\
\hline $60 \%$ choline chloride & 2.00 & 2.00 \\
\hline Vitamin premix & 0.30 & 0.30 \\
\hline Mineral premix & 1.00 & 1.00 \\
\hline Salt (NaCl) & 2.00 & 2.00 \\
\hline DL- methionine & 2.00 & 2.00 \\
\hline Limestone & 10.99 & 17.79 \\
\hline Dicalcium phosphate & 12.29 & 0.00 \\
\hline \multicolumn{3}{|l|}{ Calculated nutrient content } \\
\hline Available phosphorus (\%) & 0.4 & 0.2 \\
\hline Total phosphorus (\%) & 0.8 & 0.5 \\
\hline Calcium (\%) & 1.0 & 1.0 \\
\hline Crude protein (\%) & 21.4 & 21.4 \\
\hline Metabolisable energy $(\mathrm{kcal} / \mathrm{kg})$ & 3032 & 3036 \\
\hline \multicolumn{3}{|l|}{ Analyzed composition } \\
\hline Crude protein (\%) & 20.2 & 20.5 \\
\hline Carbohydrate (\%) & 57.8 & 57.9 \\
\hline Fat (\%) & 5.4 & 5.4 \\
\hline Phosphorus (ppm) & 5316 & 3580 \\
\hline Calcium (ppm) & 5458 & 5789 \\
\hline Copper (ppm) & 11 & 12 \\
\hline Manganese (ppm) & 106 & 103 \\
\hline Zinc (ppm) & 92 & 92 \\
\hline
\end{tabular}

Vitamin premix: vitamin A $50.00 \mathrm{MIU}$; vitamin B1 $10.00 \mathrm{~g}$; vitamin B2 30.00g; vitamin B6 20.00g; vitamin B12 0.100g; vitamin D3 $10.00 \mathrm{MIU}$; vitamin E 75.00g; vitamin K3 20.00g; Calcium D-Pantathenate $60.00 \mathrm{~g}$, Nicotinic Acid 200.00g; Folic Acid 5.00g; Biotin 235.00g; Antioxidant, Anticaking and Carrier added

Mineral premix: Se 0.200g; Fe 80.00g; Mn 100.00g; Zn 80.00g; Cu 15.00g; KCl 4.00g; $\mathrm{MgO} 0.60 \mathrm{~g} ; \mathrm{NaCO}_{3} 1.50 \mathrm{~g} ;$ I 1.00g; Co $0.25 \mathrm{~g}$

aP: Available phosphorous

12 broilers from each treatment group were randomly selected, weighed and sacrificed. Blood samples were collected from the jugular vein into vacutainer plastic blood collection tubes containing lithium heparin (BD367880). Plasma was collected after centrifugation at $3000 \times \mathrm{g}$ for $15 \mathrm{~min}$ at $4{ }^{\circ} \mathrm{C}$. The left tibia bone was removed from each sacrificed chicken and cleaned manually by removing all adhering tissues. The feed, excreta, plasma and tibia samples were used for minerals determination.

\section{Chemical analyses}

Feed samples were mixed well and kept in a plastic container. The faeces samples were collected at $24 \mathrm{~h}$ interval, by wrapping the trays under each compartment with a clean plastic sheet. All contaminants such as feathers and feed residues present on the plastic were removed before the faeces being mixed and kept in sealed plastic bags. The feed and faeces were kept at $-20^{\circ} \mathrm{C}$ before sending for analysis. Poultry feed and faeces samples were outsourced to Food \& Agriculture Analysis Laboratory, Laboratory \& Technical Services Centre, Malaysian Agricultural Research and Development Institute (MARDI) for chemical analyses. The minerals ( $\mathrm{Ca}, \mathrm{P}$, $\mathrm{Cu}, \mathrm{Mn}, \mathrm{Zn}$ ) were determined using Inductive Coupled Plasma Optical Emission Spectroscopy (ICP-OES). The apparent retention of minerals was calculated using the following equation:

Apparent nutrient retention (\%) $=($ DMfix nutrient DMfi) - (DMex nutrient DMe) / DMfi $\times$ nutrient DMfi

Where DMfi= dry matter of feed intake, $g$

DMe $=$ dry matter of excreta, $g$

\section{Statistical analyses}

All data collected were analyzed by using statistical software, IBM ${ }^{\circledR}$ SPSS for Microsoft Windows ${ }^{\circledR}$ version 22.0. Data were subjected for analysis of variance (ANOVA), and the means were tested by Duncan multiple range test for significant difference at $p<0.05$. The results were reported as means \pm standard error (SE).

\section{RESULTS}

\section{Live weight and feed conversion ratio}

The live weight and FCR of broilers were significantly improved $(p<0.05)$ in broilers fed low-aP+Mj diet compared to the controls at day 14 and day 21 (Table 2). However, live weight of broilers fed low-aP+DMj diet were similar to that fed normal-aP+DMj at both time periods. Unlike day 21, there was no significance difference in the FCR at day 14 for broilers fed lowaP+DMj and normal-aP+DMj. Regardless, the FCR for broilers receiving low-aP+Mj are significantly better than broilers fed normal-aP+DMj diet at both time periods.

\section{Minerals retention}

The apparent retentions of $\mathrm{P}, \mathrm{Ca}, \mathrm{Mn}, \mathrm{Cu}$ and $\mathrm{Zn}$ of broilers fed different dietary treatments are shown in Table 3. At both day 11-13 and day 18-20 sampling periods, $p$ retention was significantly higher $(p<0.05)$ for broilers fed with low-aP+Mj diet compared to that of control diets. However, Ca, Mn, Cu and $\mathrm{Zn}$ retentions did not differ significantly among dietary treatments at both sampling periods, although broilers fed with low-aP+Mj diet are generally higher than that of normal-aP+DMj and low-aP+DMj. 
Table 2 - Live weight and feed conversion ratio (FCR) of broilers fed normal-available $\mathrm{P}$ and low-available $p$ diets.

\begin{tabular}{|c|c|c|c|}
\hline \multirow[t]{2}{*}{ Parameter } & \multicolumn{3}{|c|}{ Dietary treatments } \\
\hline & Normal-aP+DMj & Low-aP+Mj & Low-aP+DMj \\
\hline \multicolumn{4}{|l|}{ Day 14} \\
\hline Live weight (g/bird) & $379.3 \pm 6.0^{b}$ & $404.3 \pm 0.9^{a}$ & $380.5 \pm 7.9^{b}$ \\
\hline FCR & $1.495 \pm 0.023^{a}$ & $1.328 \pm 0.014^{b}$ & $1.505 \pm 0.036^{a}$ \\
\hline \multicolumn{4}{|l|}{ Day 21} \\
\hline Live weight (g/bird) & $673.8 \pm 4.2^{b}$ & $719.3 \pm 10.7^{a}$ & $677.2 \pm 6.4^{\mathrm{b}}$ \\
\hline FCR & $1.580 \pm 0.012^{b}$ & $1.458 \pm 0.017^{c}$ & $1.663 \pm 0.013^{\mathrm{a}}$ \\
\hline
\end{tabular}

Data represent the means \pm SE of 4 replicate cages with 10 chickens for each cage.

a-c Means in the same row with different superscripts differ significantly $(p<0.05)$.

aP: Available phosphorus

Mj: Freeze-dried active M. jalaludinii phytase

DMj: Oven-dried deactivated M. jalaludinii phytase

FCR: feed conversion ratio

Table 3 - Apparent retention of phosphorus (P), calcium (Ca), manganese (Mn), copper $(\mathrm{Cu})$ and zinc $(\mathrm{Zn})$ of broilers fed normal-available $\mathrm{P}$ and low-available $\mathrm{P}$ diets.

\begin{tabular}{lccc}
\hline $\begin{array}{l}\text { Minerals } \\
\text { (\%) }\end{array}$ & & Dietary treatments & \\
\cline { 2 - 4 } Day 11-13 & Normal-aP+DMj & Low-aP+Mj & Low-aP+DMj \\
P & & & $76.8 \pm 2.07^{\mathrm{ab}}$ \\
Ca & $67.5 \pm 1.03^{\mathrm{b}}$ & $83.5 \pm 5.02^{\mathrm{a}}$ & $70.6 \pm 2.18$ \\
Mn & $71.7 \pm 3.24$ & $79.6 \pm 3.01$ & $59.8 \pm 6.63$ \\
Cu & $56.2 \pm 2.01$ & $62.3 \pm 6.98$ & $33.7 \pm 8.46$ \\
Zn & $34.3 \pm 7.34$ & $55.5 \pm 5.71$ & $59.4 \pm 5.37$ \\
\hline Day 18-20 & $56.5 \pm 4.21$ & $66.2 \pm 7.90$ & $75.5 \pm 0.82^{\mathrm{ab}}$ \\
P & & & $80.0 \pm 5.55$ \\
Ca & $72.0 \pm 3.72^{\mathrm{b}}$ & $82.9 \pm 0.47^{\mathrm{a}}$ & $52.5 \pm 9.67$ \\
Mn & $77.7 \pm 2.40$ & $82.9 \pm 1.46$ & $42.3 \pm 5.13$ \\
Cu & $54.8 \pm 5.87$ & $71.1 \pm 2.23$ & $59.2 \pm 9.01$ \\
Zn & $38.2 \pm 4.90$ & $51.4 \pm 2.77$ & $67.3 \pm 1.94$ \\
\hline
\end{tabular}

Data represent the means \pm SE of 4 replicate cages with 10 broilers for each cage.

a-b Means in the same row with different superscripts differ significantly $(p<0.05)$.

aP: Available phosphorus

Mj: Freeze-dried active M. jalaludinii phytase

DMj: Oven-dried deactivated M. jalaludinii phytase

\section{Tibia minerals}

The results of $\mathrm{Mj}$ supplement on the mineral contents of tibia bones are presented in Table 4. Broilers receiving low-aP+Mj diet had similar $\mathrm{P}$ and
Zn concentration in the tibia bone as those receiving normal-aP+DMj diet, but broilers fed low-aP+DMj diet had significantly lower concentrations $(p<0.05)$. However, Ca was more concentrated $(p<0.05)$ in tibia

Table 4 - Mineral contents ( $\mathrm{P}, \mathrm{Ca}, \mathrm{Mn}, \mathrm{Cu}, \mathrm{Zn}$ ) in tibia bone of broilers fed normal- available $\mathrm{P}$ and low-available $\mathrm{P}$ diets.

\begin{tabular}{|c|c|c|c|}
\hline \multirow{2}{*}{$\begin{array}{l}\text { Minerals } \\
\text { (ppm) }\end{array}$} & \multicolumn{3}{|c|}{ Dietary treatments } \\
\hline & Normal-aP+DMj & Low-aP+Mj & Low-aP+DMj \\
\hline$P$ & $28707 \pm 393^{a}$ & $29737 \pm 493^{a}$ & $27071 \pm 297^{b}$ \\
\hline $\mathrm{Ca}$ & $50861 \pm 907^{b}$ & $52311 \pm 484^{a}$ & $51858 \pm 317^{a b}$ \\
\hline $\mathrm{Mn}$ & $1.57 \pm 0.03^{b}$ & $1.72 \pm 0.04^{a}$ & $1.49 \pm 0.03^{b}$ \\
\hline $\mathrm{Cu}$ & $1.92 \pm 0.05$ & $2.00 \pm 0.09$ & $1.82 \pm 0.06$ \\
\hline $\mathrm{Zn}$ & $60.23 \pm 1.57^{a}$ & $59.95 \pm 1.65^{a}$ & $56.75 \pm 0.85^{b}$ \\
\hline
\end{tabular}

Data represent the means \pm SE of 4 replicate cages with 10 broilers for each cage.

a-b Means in the same row with different superscripts differ significantly $(p<0.05)$.

aP: Available phosphorus

Mj: Freeze-dried active M. jalaludinii phytase

DMj: Oven-dried deactivated M. jalaludinii phytase 


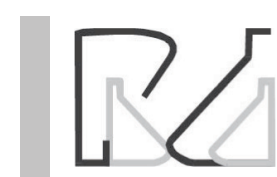

bone of broilers fed with low-aP+Mj diet than those fed normal-aP+DMj diet, but similar to those fed lowaP+DMj diet. While for Mn: broilers fed low-aP+Mj diet had a higher concentration than the other two dietary treatment groups $(p<0.05)$. However, no significant differences were observed among dietary treatments on tibia Cu content.
Mitsuokella Jalaludinii Supplementation Improved Nutrient Utilization of Broilers Fed Low-Available Phosphorus Diet

\section{Plasma minerals}

Table 5 shows the effect of $\mathrm{Mj}$ supplement on the mineral contents in blood plasma. The plasma of broilers fed normal-aP+DMj showed higher levels of $\mathrm{P}$ and $\mathrm{Cu}$ than the other dietary groups $(p<0.05)$. However, Ca content was significantly lower $(p<0.05)$

Table 5 - Mineral contents ( $\mathrm{P}, \mathrm{Ca}, \mathrm{Mn}, \mathrm{Cu}, \mathrm{Zn}$ ) in blood plasma of broilers fed normal- available $\mathrm{P}$ and low-available $\mathrm{P}$ diets.

\begin{tabular}{lccc}
\hline Minerals $(\mathrm{ppm})$ & & Dietary treatments & Low-aP+DMj \\
\cline { 2 - 4 } & Normal-aP+DMj & Low-aP+Mj & $111.7 \pm 0.7^{\mathrm{b}}$ \\
$\mathrm{P}$ & $117.7 \pm 0.7^{\mathrm{a}}$ & $72.38 \pm 1.50^{\mathrm{ab}}$ & $76.02 \pm 2.00^{\mathrm{a}}$ \\
$\mathrm{Ca}$ & $69.88 \pm 1.46^{\mathrm{b}}$ & $0.08 \pm 0.01$ & $0.09 \pm 0.01$ \\
$\mathrm{Mn}$ & $0.08 \pm 0.01$ & $0.29 \pm 0.01^{\mathrm{b}}$ & $0.24 \pm 0.01^{\mathrm{c}}$ \\
$\mathrm{Cu}$ & $0.38 \pm 0.02^{\mathrm{a}}$ & $5.37 \pm 0.30$ & $5.33 \pm 0.11$ \\
\hline $\mathrm{Zn}$ & $4.98 \pm 0.04$ & &
\end{tabular}

Data represent the means \pm SE of 4 replicate cages with 10 broilers in each cage.

${ }^{a-c}$ Means in the same row with different superscript differ significantly $(p<0.05)$

aP: Available phosphorus

Mj: Freeze-dried active M. jalaludinii phytase

DMj: Oven-dried deactivated M. jalaludinii phytase

in the normal-aP+DMj group in comparison to the lowaP+DMj group. There was no significant difference in $\mathrm{Mn}$ and $\mathrm{Zn}$ concentrations of plasma among all dietary groups.

\section{DISCUSSION}

Since monogastric animals such as poultry lack digestive phytase to hydrolyze phytates in the feed, inorganic $P$ in the form of dicalcium phosphate is often added to their diet to meet the nutrient requirement. However, this practice gave rise to environmental problems, as excessive amount of $\mathrm{P}$ is released through the excreta. Potentially, addition of phytase enzyme into poultry feed can eliminate the need to add inorganic $P$, thereby reducing $P$ pollution (Bhavsar \& Khire 2014) while reducing feed cost (PR New Wire, 2015). Moreover, supplementation of phytase is known to reduce the anti-nutritional effects of phytates and improve the digestibility of nutrients by releasing chelated or bound nutrients such as minerals, proteins and starches (Kiarie et al., 2015; Qvirist et al., 2017).

The phytase produced in $M$. jalaludinii has been demonstrated to be active at low pH (2.5 - 7.0) (Lan et al. , 2012). This $\mathrm{pH}$ range offers an advantage to nutrient digestion, as the upper part of the poultry digestive tract including the crop, proventriculus and gizzard have $\mathrm{pH}$ of $5.5,4.4$, and 3.5 respectively (Dersjant-Li et al., 2015). In the present study, an improvement in growth performance was observed in broilers fed low-aP supplemented with freeze-dried $M$. jalaludinii phytase (low-aP+Mj diet). This result indicates that $\mathrm{Mj}$ is capable of breaking down protein-phytate complexes, thus facilitates the release of nutrients for digestion and utilization in the broilers.

The present study showed that freeze-dried $M$. jalaludinii enhanced $p$ retention significantly $(p<0.05)$ as compared with the broilers fed with normal diet (Table 3). This finding is congruent with the meta-analysis on the effects of phytase supplementation on $\mathrm{P}$ retention conducted by Bougouin et al., (2014) which showed the positive effect of phytase supplementation in $\mathrm{P}$ retention for both layers and broilers. Ca retention was comparable in all dietary treatments at both sampling periods. This result was similar to that reported by (Ajith et al., 2018), who observed no significant difference in Ca retention for broilers supplemented with laboratoryproduced phytase from Aspergillus foetidus.

Overall, the inclusion of $\mathrm{Mj}$ did not have significant effect in $\mathrm{Mn}, \mathrm{Cu}$ and $\mathrm{Zn}$ although it showed better retention numerically in treatment groups fed with $\mathrm{Mj}$ at both sampling periods in comparison to those given normal diet as well as those with DMj diet. Phytase is known to help simple stomach animals such as broilers digest phytate, thus releasing nutrients trapped within the phytate complex, potentially improve mineral retention in these animals (Camden et al., 2016). However, Aoyagi \& Baker (1995) did not observe significant $\mathrm{Cu}$ retention when microbial phytase was included in the dietary treatment. Roberson \& Edwards (1994) also could not find any improvement for $\mathrm{Zn}$ retention in broiler chickens fed 
with phytase. Discrepancies in the results probably arise due to various factors like feeds, levels of phytase included in the feed, as well as animal factors such as age, breeds of chickens, genetics and sex (Kies et al., 2001). Consequently, the similar live weights between normal-aP+DMj broilers and those fed lowaP+DMj diets (Table 2) suggest that the DMj may have beneficial effect to some extend which supplements low-aP diet, even without active phytase.

The ability of microbial phytase to break down the insoluble phytate-mineral complex is expected to increase the availability of $\mathrm{P}$ and other minerals to the broilers, which might allow more minerals to be deposited in the bones and thus increase bone mineralization. In the present study, the effect of $\mathrm{Mj}$ supplementation in the low-aP diet was positively reflected by the similar $\mathrm{P}$ and $\mathrm{Zn}$ concentrations in the tibia bone of both normal-aP+DMj and low$\mathrm{aP}+\mathrm{Mj}$ diets. The concentration of tibia $\mathrm{Ca}$ on the other hand, increased significantly $(p<0.05)$ in broilers fed with low-aP+Mj diet compared to ones fed with normal-aP+DMj. This is in agreement with Viveros et al. (2002), where they have demonstrated the effect of microbial phytase supplementation to cornsoybean meal diet increased the $\mathrm{Ca}$ concentrations but not $\mathrm{P}$ concentration in tibia. It is also worth mentioning that Broz et al. (1994) reported in their findings that there was no increment of both the $p$ and $\mathrm{Ca}$ concentrations in tibia bone ash of broilers fed low-P, maize-soybean meal diet supplemented with Aspergillus niger phytase when compared to basal diet. Mj supplementation also increased the deposition of $\mathrm{Mn}(p<0.05)$, but not of $\mathrm{Cu}$. The increase in $\mathrm{Mn}$ of tibia was similar to the findings reported by Mohanna \& Nys (1999), where microbial phytase supplement enhanced $\mathrm{Mn}$ concentration in tibia. Rutherfurd et al. (2012) did not observe any improvement in Cu with additional phytase, which is similar to our finding. The effects of phytase supplementation on tibia bone mineralization are rather inconsistent probably due to several nutritional factors, such as the concentration of phytates in poultry feed, types and dosage of microbial phytase used, and grain source which influences phytate degradation rate (Dersjant-Li et al., 2017).

As opposed to tibia mineral retention, Bilal et al. (2015) reported that microbial phytase supplementation in broilers fed low-P diet showed no effect on serum $C a$, but significantly increased serum $\mathrm{P}$ concentration $(p<0.05)$. In the present study, the level of Ca was not influenced by phytase supplement, which is in agreement with the finding reported by Bilal et al. (2015). According to Sousa et al. (2015), the reason why Ca concentration in blood was not affected by phytase was probably due to $\mathrm{Ca}$ homeostasis, which is maintained by the parathyroid hormone (PTH), 1,25 di-hydroxy vitamin D $(1,25(\mathrm{OH}) 2 \mathrm{D} 3)$ and calcitonin in the intestines, bone, and kidneys. The Ca flows between these organs and extracellular fluid are regulated by these hormones, thus reducing the variation of $\mathrm{Ca}$ concentration in blood level under normal circumstances. While Bilal et al. (2015) reported an increment in the serum $p$ concentration, Kliment \& Aneglovičová (2011) found no change for $P$ content in the blood of broilers (Cobb 500) supplemented with microbial phytase. In this experiment, Mj supplementation did not affect the plasma $\mathrm{P}$ concentration in broilers (same as low$\mathrm{aP}+\mathrm{DMj}$ ), where the concentration was found to be lower than broilers fed with normal-aP diet.

The results presented in Table 5 show $\mathrm{P}$ concentrations in blood plasma of all dietary treatments were about 1.5 times higher compared to Ca concentration. Whereas, in tibia bone (Table 4), the Ca concentration was found to be about 1.8 times higher than that of $P$ concentration for all groups. This was due to the homeostasis between $\mathrm{P}$ and $\mathrm{Ca}$ as the titer of $\mathrm{Ca}$ was much higher in bone, where $99 \%$ of Ca was actually deposited in the skeleton (Proszkowiec-Weglarz \& Angel 2013).

$\mathrm{Cu}$ concentration in plasma of broilers fed with low-aP+Mj diet on the other hand was lower than that of normal-aP diet but higher than that of low-aP diet, suggesting a mild positive effect in $\mathrm{Cu}$ regulation. Lastly, plasma $\mathrm{Mn}$ and $\mathrm{Zn}$ concentration were not affected by Mj supplementation, although the overall retention of these minerals was found to be increased in percentage.

\section{CONCLUSIONS}

The inclusion of freeze-dried M. jalaludinii in lowaP diet was able to enhance live weight and feed conversion ratio of broilers. Overall, supplementation of $\mathrm{Mj}$ also improved nutrient retention in broilers compared to the controls. This study further justifies the use of Mj as an alternative source of phytase for poultry feed.

\section{ACKNOWLEDGEMENTS}

This work was funded by the Ministry of Science, Technology and Innovation of Malaysia under eScience 
Fund (06-01-04-SF1376). We would like to express our deep appreciation to our late Associate Professor Dr Sieo Chin Chin for her contribution.

\section{CONFLICT OF INTEREST}

\section{All authors certify that there is no conflict of interest} to declare.

\section{REFFERENCES}

Ajith S, Shet D, Ghosh J, Awachat VB, Bhat KS, Pal D, Elangovan AV. Effect of immobilized fungal phytase on growth performance and bone traits of broilers fed with low dietary calcium and phosphorus. Veterinary World 2018;11758-11764.

Aoyagi S, Baker DH. Effect of microbial phytase and 1,25-dihydroxycholecalciferol on dietary copper utilization in chicks. Poultry Science 1995;74(1):121-126.

Bhavsar K, Khire JM. Current research and future perspectives of phytase bioprocessing. RSC Advances 2014;4(51):26677-26691.

Bilal T, Atis $\mathrm{S}$, Keser $\mathrm{O}$. The effects of microbial phytase on serum calcium and phosphorus levels and alkaline phosphatase activities in broilers fed diets containing different levels of phosphorus. Acta Scientiae Veterinariae 2015;43:1-15.

Bougouin A, Appuhamy JA, Kebreab E, Dijkstra J, Kwakkel RP, France J. Effects of phytase supplementation on phosphorus retention in broilers and layers: a meta-analysis. Poultry Science 2014;93(8):1981-1992.

Broz J, Oldale P, Perrin-Voltz AH, Rychen G, Schulze J, Nunes CS. Effects of supplemental phytase on performance and phosphorus utilisation in broiler chickens fed a low phosphorus diet without addition of inorganic phosphates. British Poultry Science 1994;35(2):273-280.

Camden BJ, Morel PCH, Thomas DV, Ravindran V, Bedford MR. Effectiveness of exogenous microbial phytase in improving the bioavailabilities of phosphorus and other nutrients in maize-soya-bean meal diets for broilers. Animal Science 2016;73(2):289-297.

Dersjant-Li Y, Awati A, Schulze H, Partridge G. Phytase in non-ruminant animal nutrition: a critical review on phytase activities in the gastrointestinal tract and influencing factors. Journal of the Science of Food and Agriculture 2015;95(5):878-896

Dersjant-Li Y, Wealleans AL, Barnard LP, Lane S. Effect of increasing Buttiauxella phytase dose on nutrient digestibility and performance in weaned piglets fed corn or wheat based diets. Animal Feed Science and Technology 2017;234:101-109.

Haque N, Hossain A. Phytase: their biochemistry, physiology and application in poultry. International Journal of Livestock Research 2012;2(2):30-41.

Heinonen JK, Lahti RJ. A new and convenient colorimetric determination of inorganic orthophosphate and its application to the assay of inorganic pyrophosphatase. Analytical Biochemistry 1981;113(2):313-317.

Kiarie E, Woyengo T, Nyachoti CM. Efficacy of new 6-phytase from Buttiauxella spp. on growth performance and nutrient retention in broiler chickens fed corn soybean meal-based diets. Asian-Australasian Journal of Animal Sciences 2015;28(10):1479-1487.

Kies AK, Van Hemert KHF, Sauer WC. Effect of phytase on protein and amino acid digestibility and energy utilisation. World's Poultry Science Journal 2001;57(2):109-126.
Kliment M, Aneglovičová M. The effect of microbial phytase on blood performance of broiler chickens. Scientific Papers Animal Science and Biotechnologies 2011;44(1):58-61.

Lan G, Abdullah N, Jalaludin S, Ho YW. Effects of freeze-dried Mitsuokella jalaludinii culture and Natuphos ((R)) phytase supplementation on the performance and nutrient utilization of broiler chickens. Journal of the Science of Food and Agriculture 2012;92(2):266-273.

Mohanna C, Nys Y. Changes in zinc and manganese availability in broiler chicks induced by vegetal and microbial phytases. Animal Feed Science and Technology 1999;77(3):241-253.

PR News Wire. Feed enzymes market worth $\$ 1,371.03$ million by 2020 . Available from : https://www.prnewswire.com/news-releases/feedenzymes-market-worth-137103-million-by-2020-503287641. html. 2015 May [cited 2020 April].

Proszkowiec-Weglarz M, Angel R. Calcium and phosphorus metabolism in broilers: Effect of homeostatic mechanism on calcium and phosphorus digestibility. Journal of Applied Poultry Research 2013;22(3):609-627.

Qvirist L, Vorontsov E, Veide Vilg J, Andlid T. Strain improvement of Pichia kudriavzevii TY13 for raised phytase production and reduced phosphate repression. Microbial Biotechnology 2017;10(2):341-353.

Roberson KD, Edwards HM. Effects of 1,25-Dihydroxycholecalciferol and Phytase on Zinc Utilization in Broiler Chicks1. Poultry Science 1994;73(8):1312-1326

Rutherfurd SM, Chung TK, Thomas DV, Zou ML, Moughan PJ. Effect of a novel phytase on growth performance, apparent metabolizable energy, and the availability of minerals and amino acids in a low-phosphorus corn-soybean meal diet for broilers. Poultry Science 2012;91(5):11181127.

Selle PH, Cowieson AJ, Cowieson NP, Ravindran V. Protein-phytate interactions in pig and poultry nutrition: a reappraisal. Nutrition Research Reviews 2012;25(1):1-17.

Selle PH, Ravindran V, Caldwell A, Bryden WL. Phytate and phytase: consequences for protein utilisation. Nutrition Research Reviews 2000;13(2):255-278.

Sousa Jd, Albino L, Vaz R, Rodrigues K, Da Silva G, Renno L, et al. The effect of dietary phytase on broiler performance and digestive, bone, and blood biochemistry characteristics. Brazilian Journal of Poultry Science 2015;17(1):69-76

Tang HC, Chin S, Abdullah N, Mohamad R, Omar A, Chong C, et al. Production of phytase by Mitsuokella jalaludinii in semi-solid state fermentation of agricultural by-products. Sains Malaysiana 2018:47(2):277-286.

Tang HC, Sieo CC, Abdullah N, Chong CW, Gan HM, Mohd Asrore MS, et al. Effects of supplementing freeze-dried Mitsuokella jalaludinii phytase on the growth performance and gut microbial diversity of broiler chickens. Journal of Animal Physiology and Animal Nutrition 2020;104(1):116-125

Tang HC, Sieo CC, Abdullah N, Chong CW, Ho YW. Preservation of phytase enzyme produced by anaerobic rumen bacteria, Mitsuokella jalaludinii. Journal of Biochemistry, Microbiology, and Biotechnology 2017;5(1):13-17.

Viveros A, Brenes A, Arija I, Centeno C. Effects of microbial phytase supplementation on mineral utilization and serum enzyme activities in broiler chicks fed different levels of phosphorus. Poultry Science 2002;81(8):1172-1183.

Yanke LJ, Bae HD, Selinger LB, Cheng KJ. Phytase activity of anaerobic ruminal bacteria. Microbiology (Reading) 1998;144( Pt 6):1565-1573. 
